\title{
Neural measures of conscious and unconscious memory
}

\author{
Ken A. Paller \\ Department of Psychology, Northwestern University, \\ 2029 Sheridan Road, Evanston, IL 60208-2710, USA \\ Tel.: +1 847467 3370; Fax: +1 8474917859 ; \\ E-mail: kap@northwestern.edu
}

Revised 13 June 2000

Neuropsychological studies of memory disorders have played a prominent role in the development of theories of memory. To test and refine such theories in future, it will be advantageous to include research that utilizes physiological measures of the neural events responsible for memory. Measures of the electrical activity of the brain in the form of event-related potentials (ERPs) provide one source of such information. Recent results suggest that these real-time measures reflect relevant encoding and retrieval operations. In particular, distinct electrical responses have been associated with recollective processing of words and with priming of visual word-form. This source of evidence can thus enrich our understanding of both the cognitive structure and neural substrates of human memory.

\section{Introduction}

Measures of the electrical activity of the human brain can be used as powerful tools for studying human memory. However, the feasibility of this approach depends on the extent to which associations between memory functions and neurophysiological measures can be validated. Some recent advances in measuring the electrical activity of the brain in healthy human individuals will be reviewed below, with an emphasis on the use of event-related potentials (ERPs) recorded from scalp electrodes. This work will be interpreted not merely within the context of studies of brain potentials, but within a broader theoretical perspective that addresses both the cognitive structure and the neural implementation of memory functions.

Studies of memory impairments in neurological patients have had a particularly strong influence on our understanding of human memory to date $[29,63,69]$.
Despite the insights that this neuropsychological perspective has provided, it has its limitations. Analyses of cognitive functioning in patients with brain damage may not always yield an accurate or complete reflection of memory functions. When the neuropsychological approach can be combined with physiological evidence from neurologically intact subjects, however, these limitations can potentially be overcome. Before considering this alliance between neuropsychology and electrophysiology, I will outline a framework for conceptualizing certain memory functions, based primarily on studies of amnesia.

\section{The neural implementation of declarative memory}

The usefulness of studies of amnesia is perhaps a fortuitous by-product of the fact that the amnesic deficit can be highly selective. Some amnesic patients display a vast array of preserved cognitive functions, including several memory functions. Accordingly, evidence from amnesia has been widely used to develop hypotheses about the fundamental structure of memory. In particular, declarative memory has been defined behaviorally as the type of memory required for recalling and recognizing facts and events and for experiencing conscious recollection under such circumstances [132]. Although answers to a variety of questions about declarative memory must await future research, ample neuropsychological evidence supports the classification of declarative memory as distinct from other types of memory. The key empirical support for distinguishing between declarative and nondeclarative memory consists of a set of dissociations, wherein amnesic patients demonstrate poor memory when tested by recall or recognition but not when tested using various implicit memory tests, which are memory tests that make no explicit reference to prior learning episodes.

One example of an implicit memory test used to show preserved perceptual priming in amnesia is the wordidentification test $[16,36,93]$. In this test, subjects at- 

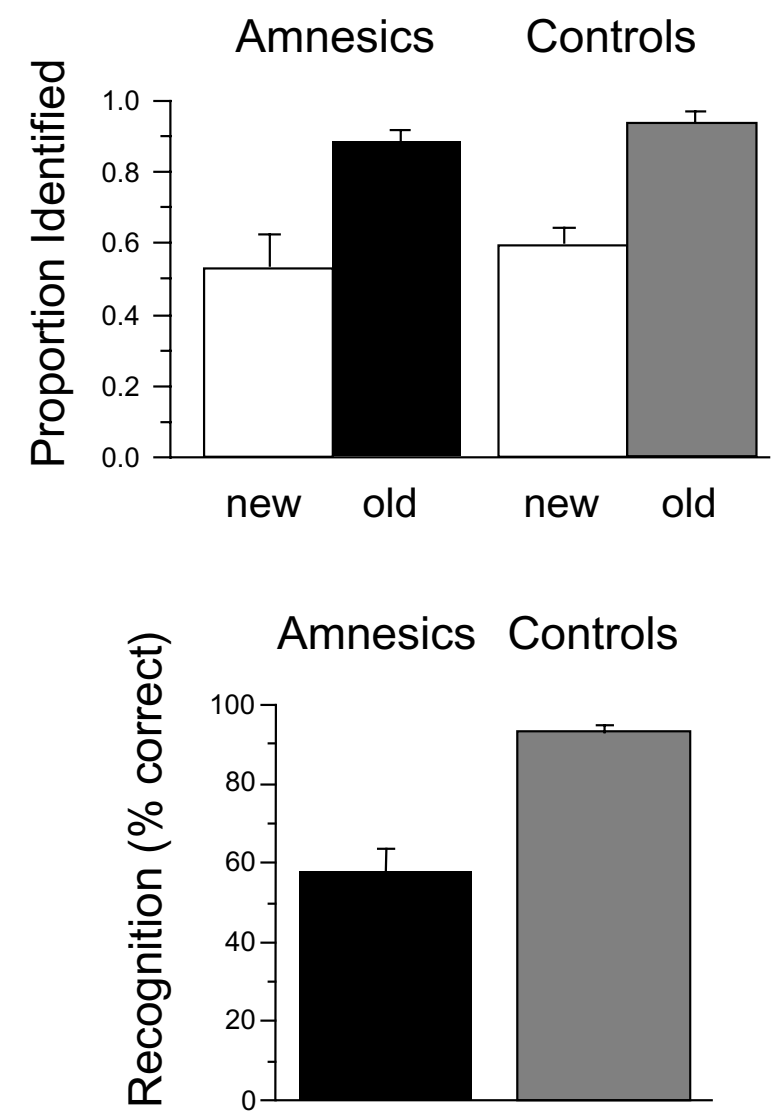

Fig. 1. Memory performance in amnesic patients and age-matched control subjects on implicit and explicit memory tests. Patients with amnesia exhibited normal word-identification priming (top) and impaired 3-alternative recognition for the same words (bottom). Figure adapted from [93].

tempt to read words presented in a degraded manner. Priming can be observed when identification is superior for words that were also presented in a study phase preceding the word-identification test. Although amnesic patients generally show normal priming in the wordidentification test, they perform poorly when asked to recognize which words were presented earlier (Fig. 1). Preserved priming in amnesia has also been verified with a wide variety of other implicit memory tests in a large literature on the topic [72,119,125,126].

Besides perceptual priming, other types of memory shown to be preserved in amnesia include motor skills, cognitive skills, simple classical conditioning, categorization learning, nonassociative learning, and working memory $[29,121,133,135]$. However, for present purposes, the contrast between declarative memory and perceptual priming will be emphasized. The hope is that this contrast will bring the fundamental divergence between declarative and nondeclarative memory into sharper focus. An advantage of emphasizing the contrast between declarative memory and priming is that identical materials can be used for testing both types of memory (i.e., in explicit memory tests and implicit memory tests, respectively). Of course, in both cases one can try to distinguish between encoding, storage, and retrieval processes. At the retrieval end, for example, these two memory phenomena can be distinguished:

(1) Conscious Recollection - when one uses declarative memory to bring to mind some prior event or some factual knowledge, with the awareness of retrieving; and

(2) Perceptual Priming - when, as the result of prior experience, behavior is changed in certain circumstances pertaining to a specific perceptual event, with no necessary sense of recollection.

One implication of the dissociations between recollection and priming - and between declarative memory and nondeclarative memory in general - is that memory should be conceived of as encompassing a set of functions, not just one ability. The fact that such distinctions are honored by neuroanatomical boundaries bodes well for further neurocognitive exploration. Imagine instead an alternative state of affairs such that declarative and nondeclarative memory depend on exactly the same neuroanatomical regions at some gross level of analysis. There might be no simple way in which declarative memory could be disrupted without also disrupting nondeclarative memory. We could still be dealing with a fundamental distinction, but if the relevant memory functions were implemented in intermingled neural tissue it would be more difficult to clarify the neural basis of the distinction. The discovery that declarative and nondeclarative memory are anatomically distinct opens the door for further investigations that can both clarify the neural bases of the distinction and elucidate the cognitive processes specifically associated with each type of memory.

According to many theoretical formulations, amnesic patients experience a dysfunction that disrupts declarative memory but leaves other types of memory entirely intact (see [64] for a collection of current views). A central challenge is to specify exactly why declarative memory has this special status. A starting point, then, is the generalization that when declarative memory breaks down in amnesia, perceptual priming can be preserved. To this can be added the further speculation that the requisite information storage for declarative memory takes place within neocortical ar- 
eas dedicated for processing the particular type of information in question $[28,67,135]$. Clearly, all declarative memories are not stored in a unitary memory storehouse in the brain. Instead, facial memories are stored in cortical areas where facial information is represented, verbal memories where verbal information is represented, and so on; memory storage in the cortex generally follows functional specialization in the cortex. Yet, the memory dysfunction of amnesia cuts across all sensory modalities and encompasses the entire range of information that can be integrated into memories for facts and events. Moreover, the disruption is not centered on simply encoding or retrieving declarative memories. Amnesic patients can generally deal with information normally in immediate memory, which belies an encoding explanation, and they can retrieve old declarative memories normally, which belies a retrieval explanation. The consensus is thus that the problem is in storing declarative memories (e.g. [19,20,33,37,66, $70,71,73,136,140])$. The dysfunctional process is not required for the initial encoding or retrieval of declarative memories, or for acquiring and expressing nondeclarative memories.

I will now present one specific conceptualization of this memory storage problem, based on some ideas I proposed earlier [82]. First, amnesia can considered as the result of a defect in a special consolidation process whereby enduring declarative memories are stored in the cerebral cortex. This consolidation process is essential because every declarative memory is composed of elements that are dispersed across multiple cortical regions, and as a result, these elements cannot be held together easily. So consolidation is the process whereby the cortical elements of a declarative memory are linked together. Normally, consolidation entails interactions between the cerebral cortex and two other brain areas, the medial temporal region and the medial diencephalon (Fig. 2). Structural neuroimaging, functional neuroimaging, and postmortem histology have shown that the brain dysfunction in amnesia tends to be localized to one or both of these two key areas (e.g., see [84]).

Declarative memories characteristically depend on high-level perceptual, cognitive, and emotional attributes represented by a set of distinct neuronal ensembles. Due to (a) the complexity of facts and events and (b) the functional organization of the cerebral cortex, this set of ensembles depends on multiple cortical regions. The experience of a fact or event in the present moment (i.e., in immediate memory) can be achieved when a set of distributed neuronal ensembles is activat- ed under the control of prefrontal networks. ${ }^{1}$ This set of neuronal ensembles can become temporarily connected via cortico-thalamic and cortico-hippocampal networks. For a short period, these temporary connections can facilitate the reactivation of the same set of ensembles. At the same time, according to the present conceptualization of consolidation, an additional function of these temporary connections is key. While corticothalamic and cortico-hippocampal networks link together a set of neocortical ensembles, they also instigate the formation of new ensembles that become an integral part of the declarative memory in question. The newly formed ensembles are referred to as "coherence ensembles" [82], because their function is to provide coherence to the dispersed neocortical representation. In other words, the temporary linking function of cortico-thalamic and cortico-hippocampal networks is ultimately replaced by coherence ensembles located in temporal lobe regions near the hippocampus. ${ }^{2}$ Speculations about the localization of these coherence modules are currently not very precise, as they are governed chiefly by neuroanatomical possibilities and by the pathological evidence from patients with focal retrograde amnesia or semantic dementia [42,52,62]. Regions that may be relevant include entorhinal cortex, perirhinal cortex, parahippocampal cortex, temporal polar cortex, adjacent transitional cortex, and perhaps orbitofrontal cortex. In any case, enduring declarative memories are, by this account, characteristically composed of a set of distributed neocortical ensembles plus associated coherence ensembles (Fig. 3).

Consolidation fundamentally entails the repeated activation of this set of neocortical storage sites, thereby mediating memory retrieval, associations with other memories, and the formation of an enduring declara-

\footnotetext{
${ }^{1}$ The role of frontal networks in activating and maintaining information in immediate memory may be only one of many memory functions that can be ascribed to the frontal lobes. However, a prefrontal contribution may not be necessary for experiencing stimulus events per se. Yet, it may be critical for experience to be removed from the present moment and thus not tightly tied to environmental stimulation [56]. Additional frontal contributions may also enter into the picture with respect to processing strategies at retrieval, as discussed below.

${ }^{2}$ The most severe cases of amnesia are caused by damage to these temporal lobe regions plus the hippocampus. In contrast, damage to these temporal lobe regions alone can lead to semantic dementia, in which remote memories may be disrupted more than recent memories [42]. Speculatively, damage to a circumscribed portion of these regions with relative sparing of the hippocampus and some adjacent temporal cortex may cause a focal retrograde amnesia [52,62], such that the patient exhibits excessive retrograde impairments along with a preserved ability to form new declarative memories.
} 


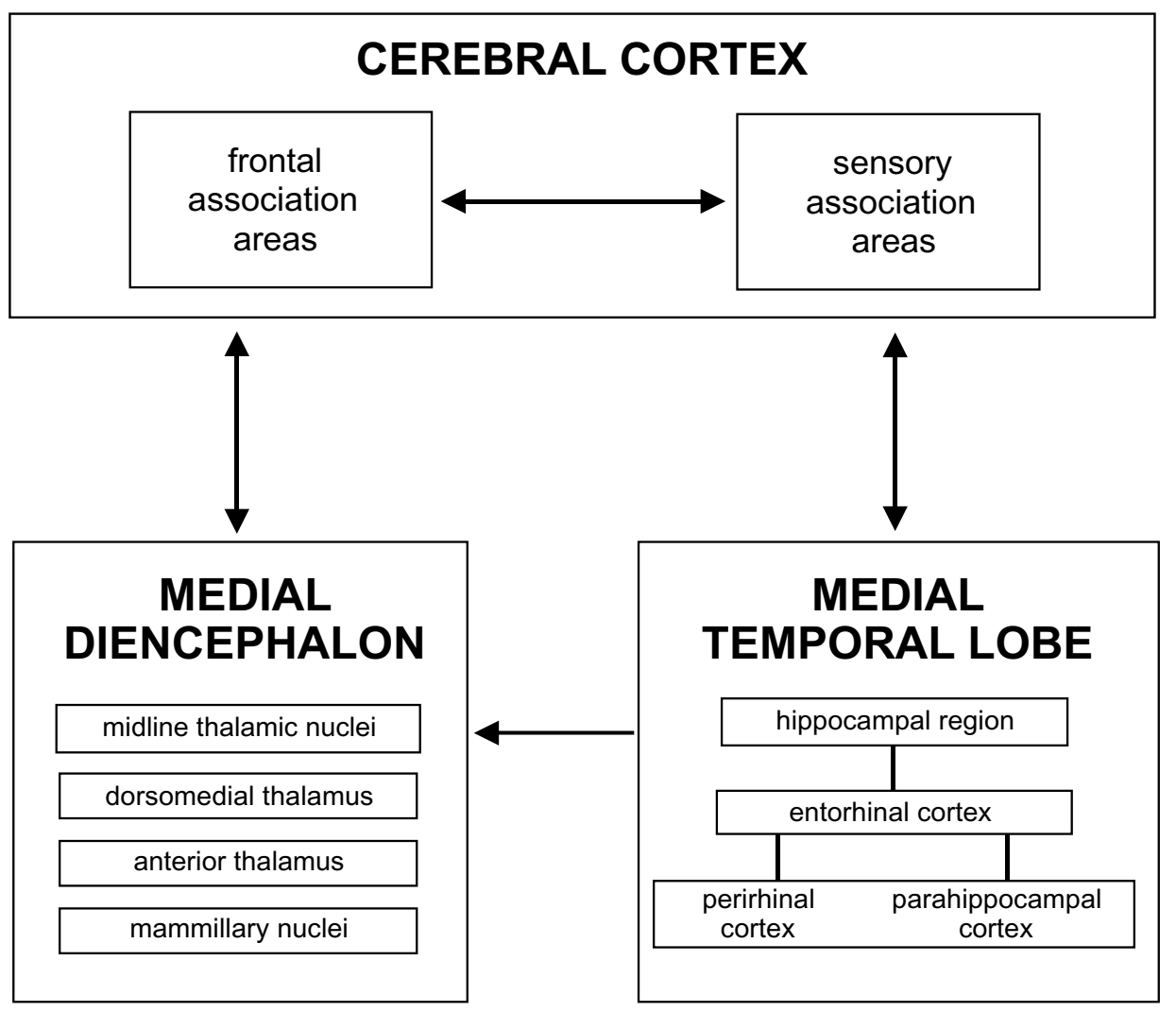

Fig. 2. Neuroanatomical regions involved in the storage of declarative memories. Figure adapted from [135].

tive memory. These several events that comprise consolidation can proceed whether or not the individual is intending to memorize or rehearse the memory, such as during the experience of related events or during sleep. Other aspects of this theoretical formulation have been described in detail elsewhere [82], but for present purposes a key implication is that declarative memory and priming can now be given these tentative neurobiological definitions:

(1) Declarative Memory is a type of neocortical memory in which the relevant plasticity occurs across many neocortical zones and storage requires a special consolidation process that is unique to this type of dispersed neocortical memory.

(2) Priming is a type of neocortical memory in which the relevant plasticity occurs within a single neocortical zone.

Although priming has most commonly been investigated using single items such as words, sometimes pairs of items have been used instead. In such cases, priming may rely on associations among separate representations. Such new associations might depend on plasticity across multiple neocortical zones rather than merely within-zone plasticity. According to the conceptualization outlined above, this would require consolidation. Indeed, implicit memory tests that tax priming for new associations often reveal impairments in amnesic patients $[15,18,65,92,120,128]$. Exceptions to this generalization $[31,74]$ may reflect the use of unitized representations such that plasticity within single neocortical zones is operative. Although other explanations for impairments in priming have been given [79], the conclusion that priming with familiar information can be preserved in amnesia has received ample support $[35,38,39]$. In short, implicit memory tests do not always show normal priming in amnesia. For priming to be normal in amnesia, performance in healthy individuals must not be mediated by recall or recognition and performance must not depend on new associations represented across distinct cortical zones. The dissociation between recollection and priming in amnesia can now be recast in neurobiological terms - recollection is impaired due to consolidation failure following disruption of either cortico-thalamic or cortico-hippocampal 


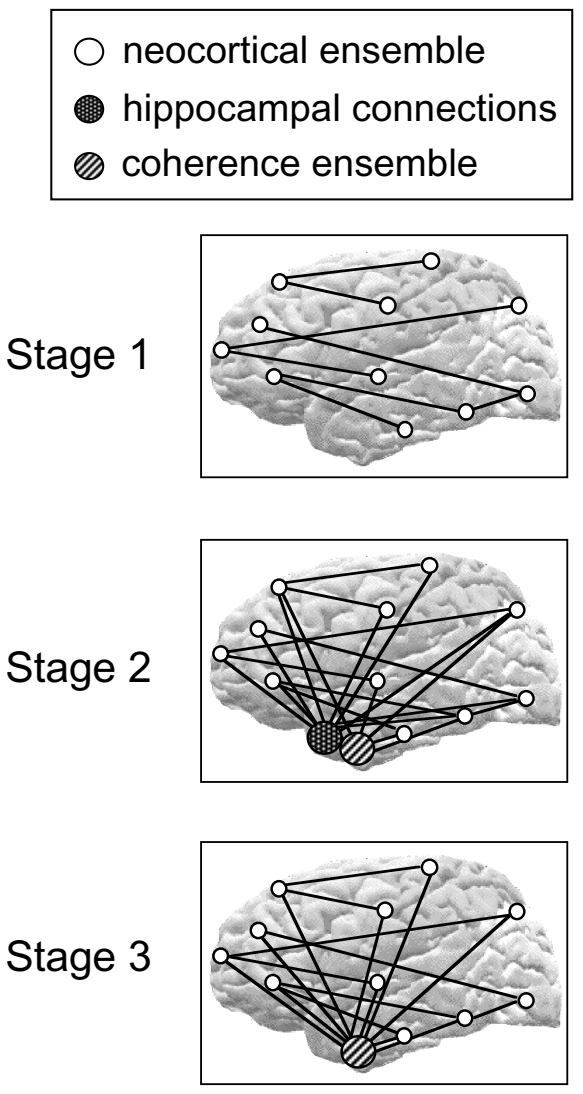

Fig. 3. Figurative depiction of the stages of consolidation of dispersed neocortical memories. In stage 1 , a fact or event is encoded via representations that involve multiple cortical regions, based on working memory processes controlled by prefrontal cortex. At about the same time, this dispersed representation begins to make contact with neurons in the medial temporal region. Hippocampal connections rapidly become part of a newly formed network so that the dispersed cortical fragments can remain connected beyond the span of immediate memory. In stage 2, coherence ensembles are formed in entorhinal, perirhinal, and parahippcampal cortex, and in adjacent cortical regions, and these become part of the network. Connections become strengthened as the memory is reactivated on subsequent occasions, while coherence ensembles develop a central role as they take on gestalt-like aspects of the memory and its relationship to other memories. Coherence ensembles thus function to maintain cohesiveness among the various parts of the declarative memory. In stage 3 , coherence ensembles take part in the reactivation of the dispersed neocortical memory without any necessary contribution from hippocampal connections.

networks, whereas priming due to plasticity within single neocortical zones is preserved.

\section{Electrophysiological measures of recollection}

Given these hypotheses about memory derived from neuropsychological research, I will now explore how

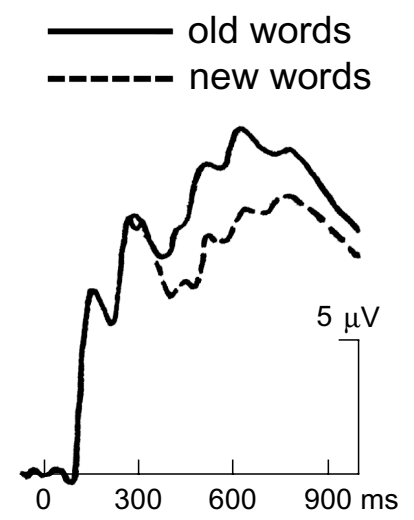

Fig. 4. An example of an old-new ERP difference (also known as an ERP repetition effect) obtained during a yes-no recognition test. The ERP response to old words was more positive than that to new words, beginning about $400 \mathrm{~ms}$ after word onset (from results obtained by Paller, Kutas, and Mayes [89]). Recordings were made from the midline parietal scalp location and positive potentials are shown as upward deflections.

relevant evidence can be obtained by measuring brain activity in healthy individuals. In particular, I will focus on ERPs, which are extracted from the electroencephalogram using signal-averaging methods. ${ }^{3}$ Noninvasive ERP recordings from the scalp reflect the summation of electrical activity generated in various brain regions, activity which summates by virtue of factors such as the spatial alignment of neurons and the synchrony of neural activity [58].

For ERP results to be useful in memory research, ERP measures must be shown to be sensitive to important memory functions. Towards this end, ERPs have been recorded during various sorts of recognition tests (e.g. $[4,26,27,48,53,76,89,106,113,116,144])$. The evidence suggests that differential ERP responses to old and new items may be useful for studying retrieval. In ERP experiments with visual words, for example, responses to old words tend to be more positive than responses to new words about 400 to $800 \mathrm{~ms}$ after word onset (Fig. 4). Similar results have also been obtained with nonverbal materials, as in one experiment in which subjects viewed color slides depicting a variety of people, places, and paintings [75]. Following ERP recordings, subjects were shown each slide a second time and

\footnotetext{
${ }^{3}$ The present discussion of ERPs and memory has a limited scope. Comprehensive reviews of the ERP literature have appeared elsewhere $[46,57,109]$. Some of the issues covered here also apply to work with other methodologies for measuring brain activity accompanying cognition. Other electroencephalographic phenomena associated with memory include EEG measures in the frequency domain [55] and slow potentials [105].
} 
asked whether they had recognized it during its initial exposure. An average of $11 \%$ of the slides fell into this category, and ERPs to these recognized slides were considerably more positive than ERPs to unrecognized slides, particularly at around $400 \mathrm{~ms}$. This result parallels findings from other experiments in which items recognized from a presentation earlier in the experiment elicited ERPs that were more positive than ERPs to new items. These reports of old-new ERP differences provide a good foundation for the suggestion that recognition processes are measurable using ERPs. ${ }^{4}$

Before accepting the claim that ERPs tap processes central to recognition, however, we must consider several features of typical recognition paradigms that cloud the issue. First, both the time to make a recognition judgment and the confidence with which it is made may differ considerably between old and new items. ${ }^{5}$ Second, the fact that subjects are required to detect recognized items may call into play target-detection operations that differ for old and new items. Third, the subjective probability of old and new items may differ, whether or not actual stimulus probabilities are matched. All of these factors are known to influence ERPs, so these confounding factors are particularly worrisome. In short, it can be problematic to distinguish electrophysiological (or other physiological) effects due to these nonspecific factors from effects due to recognition per se. Furthermore, and most important in the present context, simply comparing old and new items in a recognition paradigm does not take into account the idea that both recollection and priming occur in such a situation.

Although several lines of evidence are consistent with the hypothesis that ERPs are sensitive to recog-

\footnotetext{
${ }^{4}$ ERPs have also been used to show that neurocognitive events at the time information is first encoded are predictive of whether they will be remembered later. The phenomenon of an ERP difference computed as a function of later memory performance, sometimes called $D m$, has been observed with explicit memory tests such as recall and recognition (e.g. $[23,53,80,89,94,116])$ but not with implicit memory tests such as stem completion or word identification [80, 88]. More recently, such effects have been observed with fMRI [10, $25,143]$, with intracranial ERP recordings in the medial temporal region [24], and with other EEG measures [55,145].

${ }^{5}$ In one experiment, for example, ERPs were averaged separately according to confidence measures (an analysis reported in [81] of data collected by Paller, Kutas and Mayes [89]). ERPs were more positive for words categorized with high confidence than with low confidence. In fact, ERPs in other paradigms are similarly correlated with decision confidence $[41,107]$. Confounds with recognition confidence can thus contribute to observed old-new ERP differences, particularly when hits to old items are more confident than correct rejections to new items. Confidence judgments tend to be insufficiently sensitive to ameliorate this problem.
}

nition processes, much of the early evidence fell short of being conclusive. Johnson and colleagues [47,48] showed that ERPs correlated with increases in memory strength as study words were repeated, which would be expected for an ERP correlate of recognition strength. Bentin and colleagues [6,7] recorded old-new ERP differences and proposed that ERPs are sensitive to both implicit and explicit aspects of memory performance. However, the methods used were insufficient for disentangling these different processes because both types of memory were influenced by the manipulations. Likewise, ordinary contrasts between implicit and explicit memory tests using the stem-completion methodology have been insufficient for fractionating out valid neural correlates of implicit and explicit memory $[3,81,138]$. Smith and Halgren [131] interpreted their ERP results in terms of a distinction between memory strength and contextual retrieval as two separate bases for recognition judgments $[1,43,60]$. Lists of 20 abstract words were arranged such that the same 10 words occurred in every list, and subjects were instructed to press a button whenever one of these repeating words was presented. Recognition accuracy increased across the six lists in healthy individuals and in patients with unilateral anterior temporal lobectomies (performed for relief of medically intractable epilepsy). Smith and Halgren [131] suggested that increases in memory strength were normal in all patients, but that the ability of patients with left-hemisphere excisions to use contextual retrieval was compromised and that this explained attenuated old-new ERP differences that were found in those individuals. In other words, old-new ERP differences were thought to reflect contextual retrieval. This conclusion was not endorsed by the authors of a similar study [114], who found no relationship between the magnitude of old-new ERP effects and verbal memory performance in epileptic patients.

An alternative position was advocated by Rugg and colleagues, who used several lines of evidence to argue that old-new ERP differences reflect relative familiarity and not recollection. The central assumption, from two-process models of recognition, was that relative familiarity (a discrepancy between the level of familiarity cued by an item and the level of familiarity that the individual would expect a priori) can function as a basis of recognition judgments. According to Jacoby and Dallas [43], for example, familiarity can be based on fluent perceptual processing of repeated items. In one study, injections of the anticholinergic agent scopolamine were found to produce a decrement in recognition performance along with an increase in old-new 
ERP differences [96]. The authors suggested that the drug had a detrimental effect on recollection that coincided with an increase in the extent to which recognition judgments were based on relative familiarity (i.e., thus endorsing a functional account of ERP repetition effects antithetical to the hypothesis of Smith and Halgren [131]). In other experiments, the finding that oldnew ERP differences were apparent for low-frequency words but not for high-frequency words was interpreted in relation to the idea that low-frequency words give rise to a higher level of relative familiarity, an idea that may also explain the recognition advantage for such words [108,111]. However, if we grant that recognized low-frequency words also tend to engage more recollection [32], this evidence is equivocal with respect to associating ERPs with familiarity versus recollection.

Conclusively determining whether or not ERPs can be linked to recollection versus other factors required a different empirical approach. In an attempt to isolate neuronal activation specific to recollection, Paller and Kutas [88] introduced a procedure based on producing behavioral dissociations between recollection and priming. Instead of comparing ERPs to old versus new words, ERPs were compared between different types of old words presented during an implicit memory test, the word-identification test. A levels-of-processing manipulation at study was used to produce a memory dissociation of the sort previously demonstrated. When subjects study words by focusing on word meaning for one set of words and letter identity for another set of words, the two sets of words are generally associated with different levels of recall performance and similar levels of priming $[43,102,104]$, although this generalization is controversial $[8,17,103]$. Of course, memory tests cannot be relied on for absolutely pure measures of underlying memory phenomena (i.e., memory tests are not process-pure). Nonetheless, reliable dissociations between certain priming tests and explicit memory tests provide a key ingredient for a convincing interpretation of the ERP findings. The two types of studied words under scrutiny differed in the extent to which recollection was provoked, but they were the same with respect to (a) physical stimulus characteristics, by virtue of the counterbalanced design, (b) the behavioral responses made in the implicit memory test, and (c) the magnitude of priming. Accordingly, we hypothesized that the ERP difference wave was an electrophysiological correlate of recollection, distinct from the influence of priming or other confounding factors. These results constitute the first published evidence to strongly support the hypothesis that the subjective experience of recollection can be monitored via measures of the electrical activity of the brain.

Several other methods have also been used to reveal ERPs associated with recollection. One method is to require subjects to respond according to their experience (i.e., a full experience of recollection is to be given a "remember" response and a context-free feeling of familiarity a "know" response), as in prior behavioral experiments (e.g. [32,142]). When applied in ERP studies, results showed that ERPs were sensitive to recollective processing, although the specific nature of ERP differences associated with pure familiarity varied across studies $[22,109,129]$. Indeed, the early portion of ERP repetition effects have been linked to N400 reductions and occasionally ascribed to familiarity in the absence of recollection. However, an alternative interpretation of N400 differences in memory paradigms is that they reflect conceptual priming and working memory operations as typically engaged during prose comprehension [78].

Another methodology for investigating electrophysiological correlates of recollection has been to include a memory test in which source information must be retrieved (e.g., the voice of spoken information). In several studies, ERP differences were found between recognized old items according to whether the source was also correctly remembered or not $[45,124,141,147$, 148]. Based on the assumption that recollection would tend to occur more often for words attributed to the correct source than for words attributed to the wrong source, the findings were interpreted as evidence that ERPs are sensitive to recollective processing (see also [130]).

In addition, the hypothesis of Paller and Kutas [88], that an ERP correlate of recollection could be isolated based on an appropriate encoding manipulation, was substantiated by results from several follow-up experiments. First, a variation of the design was used along with a between-subjects manipulation of the extent to which conscious recollection occurred [90]. These results showed that the ERP correlate of recollection was not limited to the particular circumstances in the initial experiment, and that it was larger in subjects more likely to experience recollection. Furthermore, in the same experimental paradigm, abnormal ERP responses were observed from elderly participants with mild declarative memory impairments [50]. Another ERP study was conducted using a group of amnesic patients with moderate to severe declarative memory impairments compared to age-matched control subjects [78]. The magnitude of late positive ERP differences was found 
to be correlated with the extent of memory impairment in these patients, either measured via memory tests for the words used in the experiment or via standardized neuropsychological tests.

An analogous experimental strategy has also been used in the auditory modality [34]. Spoken words were presented under two different study conditions using a levels-of-processing procedure. Priming of lexical decision response time was the same across different study conditions, whereas recognition was not. We interpreted test-phase ERPs that differed between study conditions as reflections of the retrieved visual imagery engaged when the words were heard. This differential imagery took place both during study and test, even though the test condition did not require it. Indeed, we speculated that our electrophysiological measures reflected the recapitulation of this visual imagery, a prominent factor supporting accurate word recognition.

ERP correlates of recollection can also be elicited by photographs of faces $[85,86]$. In these experiments, participants were first asked to memorize a set of faces that were each accompanied by a voice simulating the voice of that individual (e.g., "I'm Alison and I won the Boston Marathon twice"). In a test phase, ERPs to these faces ("remember faces") showed reliable differences in comparison to ERPs to new faces as well as to ERPs to faces that had been presented in the study phase without voices and with instructions to forget ("forget faces"). Importantly, results from a separate behavioral experiment showed that perceptual priming did not differ between the two types of studied faces, whereas remember faces were later recognized much more accurately. The ERP difference between the two types of studied faces was therefore taken as a neural correlate of recollection, disentangled from ERP correlates of priming. Of course, it will also be necessary to specify the full range of cognitive processes that contribute to recollective experience in these situations.

In this regard, a reasonable speculation is that retrieval occurs through interactions between frontal and posterior cortical areas. Results from applying both ERP and fMRI methods in the same face recollection paradigm [95] have supported this speculation. Furthermore, other ERP results likewise suggest that frontal regions are particularly important for successful episodic retrieval [97-99,139], as do many recent results from neuroimaging and neuropsychology $[77$, $115,127]$.

In future, our understanding of the neural substrates of recollection is likely to be enhanced by combining neuropsychological approaches with methods for mea- suring neural correlates of memory functions. However, several challenges must be faced when attempting to localize the sources of scalp-recorded ERPs, and when attempting to establish a correspondence between ERP correlates of recollection and fMRI correlates of recollection. First, the brain events that lead to an ERP response are not necessarily identical to those that will lead to an fMRI response [58,59,61,110]. Furthermore, recollective processing will tend to engage a large set of brain areas, such that the scalp-recorded electrical activity will reflect a combination of activity from those sources. When a large number of intracranial sources are activated at the same time in this manner, it may be exceedingly difficult to unambiguously identify the separate sources based on scalp data. In some circumstances, as when very focal effects are achieved in well-understood experimental contrasts, topographic information can be used to suggest that particular brain regions may be active. Added evidence from other sources (e.g., magnetoencephalography, neuropsychology, transcranial magnetic stimulation, etc.) can be used to build a stronger case for localization of function. Nonetheless, combining ERP and fMRI evidence from the same behavioral paradigm can be expected to provide many additional insights into the brain events responsible for recollection.

Topographic findings in studies of ERP correlates of recollection have converged in some respects and diverged in others. Most consistently, both parietal and frontal scalp effects have been observed. Often, the parietal effects are found to be larger over the left hemisphere and the frontal effects over the right hemisphere, but it is likely that both hemispheres are involved. Some topographic differences across studies may reflect the different sorts of memorial information retrieved, which would be expected to depend on different neocortical regions. At the time of retrieval, active regions presumably include the parts of neocortex where specific information is stored as well as coherence ensembles implementing the linking function additional consolidation will occur when information is retrieved and when it is then related to other stored information. An important goal for future experimentation will be to determine whether neural correlates of consolidation can be distinguished from neural correlates of memory search, retrieval, evaluation, and recollection.

In sum, studies of old-new ERP differences led to divergent hypotheses about relationships between ERPs and memory retrieval, whereas subsequent studies succeeded in isolated ERP correlates of recollective pro- 
cessing. Due to the fact that both recollection and priming tend to occur when studied items are presented in a memory test, conventional analyses of old-new ERP effects tend to be equivocal with respect to isolating ERPs associated with one type of memory or the other. Demonstrations of ERP correlates of recollection were most successful when (1) ERPs were recorded during recognition tests as well as when subjects were not required to make overt recognition responses; (2) ERPs were contrasted as a function of study conditions that differentially influenced declarative memory but did not differentially influence the magnitude of priming; and (3) behavioral measures were included to confirm the memory dissociations. The idea that observations can be made of the neural events responsible for conscious recollection is important because such observations should prove helpful for testing theories about the neurophysiology of declarative memory.

\section{Electrophysiological measures of perceptual priming}

Perceptual priming differs from recollection in many respects, and experimental juxtapositions of recollection and priming can potentially provide insights into the distinctive nature of these two memory phenomena. To reveal neural correlates of priming, an approach analogous to that used by Paller and Kutas [88] was adopted by taking advantage of manipulations that influence priming more than recollection. In one experiment, words were displayed at study either as complete words or by showing one letter at a time in quick succession [91]. Priming was enhanced in the former relative to the latter condition, whereas recognition was relatively unaffected. ERPs corresponding to this differential priming were recorded during the priming test, when all words were displayed as complete words. This ERP difference between conditions was interpreted as a reflection of differential processing of visual word-form (i.e., words represented as whole units), given that so many other aspects of word processing were matched in the two study conditions. The ERP difference can thus be taken as an ERP correlate of just one subtle aspect of priming pertaining to visual word form, and it may be insensitive to other possible consequences of prior experience with a word and to other changes that could contribute to behavioral measures of priming. The ERP correlate of visual word-form priming [91] differed from ERP correlates of recollection recorded in a largely similar paradigm [90] in that it occurred slightly earlier and had a focal topography centered at occipital scalp locations.

These results were substantiated in a subsequent experiment in which priming was manipulated by presenting words either spelled forward or backward [87]. In this experiment, Paller and Gross [87] used both implicit and explicit memory tests, in different subjects. In the implicit memory test (detecting proper names among other words), ERPs showed a reduced response for the backward-study condition that was interpreted as an ERP correlate of visual word-form priming. On the other hand, in the explicit memory test (yes-no recognition) the ERPs were predominated by ERP correlates of recollection in the form of a positive shift for both study conditions, particularly the backward-study condition. Presumably, ERPs associated with recollection overlapped with and obscured the early ERP differences that were apparent during the implicit memory test. These results thus provided further support for the idea that ERPs from posterior scalp locations can include an electrophysiological correlate of visual word-form priming (see also [49,51]). In addition, these ERP correlates of priming confirm the necessity of valid experimental procedures to disentangle ERP correlates of implicit and explicit memory, which can be indistinguishable in standard old/new contrasts.

A few other methods have also been used to search for ERP correlates of priming. In several ERP experiments, a masked repetition priming procedure was used in which subjects were unaware of the priming [122, 123]. Posterior ERP effects were found for words when the same word had been presented about $2.5 \mathrm{~s}$ earlier in masked format, and so may also reflect a sort of perceptual priming. However, the fact that the retention interval was considerably shorter than in the priming studies above could mean that quite different processes are operative. Presumably, repetition effects within working memory rely on different mechanisms than repetition effects at longer delays, although this remains to be investigated fully. In another experiment, ERPs were elicited by new words, deeply encoded old words, and shallowly encoded old words, and a putative ERP correlate of priming was observed from 300-500 ms [112]. This positive response for old relative to new words was observed whether or not the old words were recognized and regardless of encoding task or whether an implicit or explicit memory test was given. The functional features of this potential are thus consistent with an ERP correlate of priming. Given the different approach used in this study, however, it is unclear whether the ERP effects reflect the same process or processes as in the 


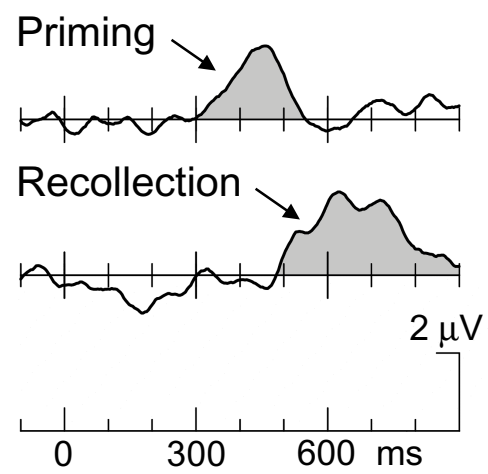

Fig. 5. Brain potentials specifically associated with visual word-form priming and recollection. The upper waveform was computed by subtracting brain potentials elicited by words previously viewed forward or backward; priming magnitude was relatively greater in the studied-forward condition [87]. The lower waveform was computed by subtracting brain potentials elicited by words previously studied in an imagery task versus an orthographic task; recollection was relatively stronger in the imagery condition [88]. Recordings were made from the midline parietal scalp location and positive potentials are shown as upward deflections.

prior results from study phase manipulations of visual word-form [87,91].

A direct comparison between an electrophysiological correlate of recollection and an electrophysiological correlate of perceptual priming is shown in Fig. 5. These measures of brain events underlying recollection and priming provide new empirical footholds for theoretical advances regarding the critical differences between memories that are accessible to consciousness and those that are not - and perhaps between conscious and unconscious events in general. In particular, electrophysiological correlates of priming are needed to help clarify the significance of priming. While priming can be considered a type of unconscious memory measured in certain contrived situations, much controversy surrounds the question of how priming contributes to memory and/or perceptual functions under normal circumstances. Dissociations between recollection and priming in amnesic patients and in healthy subjects, particularly findings that priming can occur even when an individual cannot explicitly distinguish between old and new items, support the view that priming effects do not contribute to performance on explicit memory tests (e.g. $[13,14])$. However, priming may contribute to other functions. One position, championed by Wiggs and Martin [146] is that perceptual priming may result from decreased neural activity following perceptual learning, which may be the essence of efficient perceptual processing. Data from neuronal recordings, neuroimaging, and neuropsychology support this view. In ventral temporal areas of monkey visual cortex, some neurons tend to show reduced responses to stimulus repetitions or "repetition suppression" $[5,11,21]$. The characteristics of this phenomenon, such as its automatic nature, suggest that it may mediate behavioral measures of perceptual priming (although the converse result, repetition enhancement, was found in some neurons for task-relevant stimuli [68]). Repetition suppression may reflect changes in the perceptual representation of an object as the elements of the representation become refined and sharpened, and as some neurons drop out of the neuronal ensemble or ensembles critical to the object representation [21]. The alteration of cortical representations in this manner is thought to be a normal facet of perceptual learning, such that perceptual priming effects are a reflection of the more efficient perceptual processing that comes naturally with repeated experience.

At a general level, these physiological findings in monkeys are in concordance with results from neuroimaging studies in humans, despite species differences and the uncertain relationship between unit and hemodynamic responses. PET and fMRI evidence associating priming with reduced responses in occipitotemporal and other regions has been interpreted to imply that priming may result from decreased neural activity with repetition $[2,9,12,44,117,118,134]$. Moreover, despite divergence between paradigms it is conceivable that ERP correlates of visual word-form priming $[87,91]$ may correspond to the reduced occipitotemporal responses observed with PET and fMRI. However, the mapping between the electrical response (larger positive potential over occipitoparietal scalp for primed items) and the blood flow and oxygenation changes (presumably reflecting less neuronal activity in occipitotemporal cortex) is presently underconstrained. Further work that can isolate activity mediating circumscribed aspects of priming, such as priming of visual word-form, will open the door for the detailed modeling that is necessary for establishing an ERP-fMRI correspondence. If a strong correspondence can be established, these memory phenomena could be monitored with sharp spatial and temporal resolution, which would be a promising step closer to clarifying the significance of the corresponding neuronal events.

To return to the neuropsychological approach, and in line with the divergence between the brain regions required for normal declarative memory and those involved in perceptual priming, several case studies of patients with occipital damage have documented priming deficits without corresponding recognition deficits [30, 
54,137]. However, in no patient were all types of priming impaired. Indeed, it is reasonable to suppose that plasticity in correspondingly different brain regions may be responsible for priming in different types of priming test. Moreover, priming effects may often reflect a combination of facilitated processing at multiple stages rather than solely within a single computation. A yet more complicated scenario must be entertained if repetition suppression and repetition enhancement tend to occur together, as the evidence on monkey neuronal responses suggests. Results from a recent fMRI study suggest that one factor that can influence which of these two effects occurs is stimulus familiarity [40]. In fusiform regions, repetition suppression was found with novel faces and symbols, whereas repetition enhancement was found with well-known faces and symbols. However, enhanced responses with repetition may reflect explicit recognition, as found in fMRI studies of category learning and recognition with dot patterns $[100,101]$. Thus, to understand the brain substrates of priming, it will be necessary to survey multiple cortical regions with a variety of behavioral paradigms wherein recollective processing can be well controlled. As in ERP studies of memory described above, it will be necessary to use paradigms that can dissociate neural correlates of recollection from neural correlates of priming.

\section{Conclusions: Cognitive neuroscience and human memory}

Studies of amnesia have implicated certain brain areas in memory, but moving forward to a comprehensive understanding of the neural implementation of memory functions will require an alliance among multiple empirical approaches. Studies in both healthy and braindamaged people will be needed. The usefulness of electrophysiological and functional neuroimaging techniques in this regard will require experimental designs that take optimal advantage of the spatial and temporal resolution provided by each method.

Recent results support the speculation that brain potentials can provide objective measures of an unobservable phenomenon, the conscious experience of retrieving a memory. These electrophysiological correlates of conscious recollection contrast with other findings showing that different brain potentials are associated with perceptual priming of visual word-form. The further development of such contrasts between recollection and priming using this methodology should pro- vide a rich source of evidence pertaining to the neural implementation of human memory.

Such studies of the neural bases of human memory have the potential for expanding the insights gained from prior cognitive and neuropsychological studies of memory. Contrasts between recollection and priming, in particular, have launched tremendous theoretical development, although more work will be required to adequately test and develop these ideas. A tenable working hypothesis about these two phenomena, emphasized here, characterizes recollection and priming as two different types of neocortical memory. Priming is thought to depend on isolated instances of neocortical plasticity such that subsequent processing in one or more specific cortical regions is altered. In contrast, recollection is thought to require the formation of links among sets of neocortical regions in the service of creating an enduring declarative memory. Given the evidence that ERPs can be used to monitor processes associated with recollection and priming, this approach should be useful for developing more fine-grained hypotheses about the neurophysiology of the two types of memory. These efforts to understand the neural bases of human memory may thus lead ultimately to a valid biological characterization of the subjective experience of conscious recollection.

\section{Acknowledgements}

Research support was provided by grant NS34639 from the National Institute of Neurological Diseases and Stroke and by Northwestern University. I thank Marcia Grabowecky, Marta Kutas, Andrew Mayes, and Larry Squire for their input and encouragement. Parts of this paper will also appear in a book chapter ([83], including figures copyright Academic Press). Correspondence should be addressed to Ken Paller, Department of Psychology, Northwestern University, 2029 Sheridan Road, Evanston, IL 60208-2710, USA (email: kap@northwestern.edu).

\section{References}

[1] R.C. Atkinson and J.F. Juola, Factors influencing the speed and accuracy of word recognition, in: Attention and performance IV, S. Kornblum, ed., Academic Press, New York, 1973, pp. 583-612.

[2] L. Bächman, O. Almkvist, J. Andersson, A. Nordberg, B. Winblad, R. Reineck and B. Långström, Brain activation in young and older adults during implicit and explicit retrieval, Journal of Cognitive Neuroscience 9 (1997), 378-391. 
[3] R.D. Badgaiyan and M.I. Posner, Time course of cortical activations in implicit and explicit recall, Journal of Neuroscience 17 (1997), 4904-4913.

[4] S.E. Barrett, M.D. Rugg and D.I. Perrett, Event-related potentials and the matching of familiar and unfamiliar faces, Neuropsychologia 26 (1988), 105-117.

[5] G.C. Baylis and E.T. Rolls, Responses of neurons in the inferior temporal cortex in short term and serial recognition memory tasks, Experimental Brain Research 65 (1987), 614622 .

[6] S. Bentin and M. Moscovitch, Psychophysiological indices of implicit memory performance, Bulletin of the Psychonomic Society 28 (1990), 346-352.

[7] S. Bentin, M. Moscovitch and I. Heth, Memory with and without awareness: performance and electrophysiological evidence of savings, Journal of Experimental Psychology: Learning, Memory, and Cognition 18 (1992), 1270-1283.

[8] S. Bentin, M. Moscovitch and O. Nirhod, Levels of processing and selective attention effects on encoding in memory, Acta Psychologica 98 (1998), 311-341.

[9] T.A. Blaxton, S.Y. Bookheimer, T.A. Zeffiro, C.M. Figlozzi, W.D. Gaillard and W.H. Theodore, Functional mapping of human memory using PET: Comparisons of conceptual and perceptual tasks, Canadian Journal of Experimental Psychology 50 (1996), 42-56.

[10] J.B. Brewer, Z. Zhao, J.E. Desmond, G.H. Glover and J.D. Gabrieli, Making memories: Brain activity that predicts how well visual experience will be remembered, Science $\mathbf{2 8 1}$ (1998), 1185-1187.

[11] M.W. Brown, F.A. Wilson and I.P. Riches, Neuronal evidence that inferomedial temporal cortex is more important than hippocampus in certain processes underlying recognition memory, Brain Research 409 (1987), 158-162.

[12] R.L. Buckner, S.E. Petersen, J.G. Ojemann, F.M. Miezin, L.R. Squire and M.E. Raichle, Functional anatomical studies of explicit and implicit memory retrieval tasks, Journal of Neuroscience 15 (1995), 12-29.

[13] C.B. Cave, Very long-lasting priming in picture naming, Psychological Science 8 (1997), 322-325.

[14] C.B. Cave and L.R. Squire, Intact and long-lasting repetition priming in amnesia, Journal of Experimental Psychology: Learning, Memory, and Cognition 18 (1992), 509-520.

[15] L.S. Cermak, R.P. Bleich and S.P. Blackford, Deficits in the implicit retention of new associations by alcoholic Korsakoff patients, Brain and Cognition 7 (1988), 312-323.

[16] L.S. Cermak, N. Talbot, K. Chandler and L.R. Wolbarst, The perceptual priming phenomenon in amnesia, Neuropsychologia 23 (1985), 615-622.

[17] B.H. Challis, B.M. Velichkovsky and F.I.M. Craik, Levelsof-processing effects on a variety of memory tasks: New findings and theoretical implications, Consciousness and Cognition 5 (1996), 142-164.

[18] M.M. Chun and E.A. Phelps, Memory deficits for implicit contextual information in amnesic subjects with hippocampal damage, Nature Neuroscience 2 (1999), 844-847.

[19] N.J. Cohen, R.A. Poldrack and H. Eichenbaum, Memory for items and memory for relations in the procedural/declarative memory framework, Memory 5 (1997), 131-178.

[20] A.R. Damasio, Time-locked multiregional retroactivation: a systems-level proposal for the neural substrates of recall and recognition, Cognition 33 (1989), 25-62.

[21] R. Desimone, Neural mechanisms for visual memory and their role in attention, Proceedings of the National Academy of Science USA 93 (1996), 13494-13499.
[22] E. Düzel, A.P. Yonelinas, G.R. Mangun, H.J. Heinze and E. Tulving, Event-related brain potential correlates of two states of conscious awareness in memory, Proceedings of the National Academy of Science USA 94 (1997), 5973-5978.

[23] M. Fabiani, D. Karis and E. Donchin, P300 and recall in an incidental memory paradigm, Psychophysiology 23 (1986), 298-308.

[24] G. Fernández, T. Grunwald, A. Effern, N. Pezer, J. Lehnertz, N. Dümpelmann and C.E. Elger, Serial processes of declarative memory formation in the human medial temporal lobe, NeuroImage 9 (1999), S921, (Abstract).

[25] G. Fernández, H. Weyerts, M. Schrader-Boelsche, I. Tendolkar, H.G.O.M. Smid, C. Tempelmann, H. Hinrichs, H. Scheich, C.E. Elger, G.R. Mangun and H.-J. Heinze, Successful verbal encoding into episodic memory engages the posterior hippocampus: A parametrically analyzed functional magnetic resonance imaging study, Journal of Neuroscience 18 (1998), 1841-1847.

[26] D. Friedman, ERPs during continuous recognition memory for words, Biological Psychology 30 (1990), 61-87.

[27] D. Friedman and S. Sutton, Event-related potentials during continuous recognition memory, Electroencephalography and Clinical Neurophysiology, Supplement 40 (1987), 316-321.

[28] J.M. Fuster, Memory in the cerebral cortex: An empirical approach to neural networks in the human and nonhuman primate, Cambridge, Mass.: MIT Press, 1995.

[29] J.D.E. Gabrieli, Cognitive neuroscience of human memory, Annual Review of Psychology 49 (1998), 87-115.

[30] J.D.E. Gabrieli, D.A. Fleischman, M.M. Keane, S.L. Reminger and F. Morrell, Double dissociation between memory systems underlying explicit and implicit memory in the human brain, Psychological Science 6 (1995), 76-82.

[31] J.D.E. Gabrieli, M.M. Keane, M.M. Zarella and R.A. Poldrack, Preservation of implicit memory for new associations in global amnesia, Psychological Science 8 (1997), 326-329.

[32] J.M. Gardiner and R.I. Java, Forgetting in recognition memory with and without recollective experience, Memory \& Cognition 19 (1991), 617-623.

[33] M.A. Gluck, B.R. Ermita, L.M. Oliver and C.E. Myers, Extending models of hippocampal function in animal conditioning to human amnesia, Memory 5 (1997), 179-212.

[34] B. Gonsalves and K.A. Paller, Brain potentials associated with recollective processing of spoken words, Memory \& Cognition 28 (2000), 321-330.

[35] P.A. Gooding, A.R. Mayes and R. van Eijk, A meta-analysis of indirect memory tests for novel material in organic amnesics, Neuropsychologia 38 (2000), 666-676.

[36] F. Haist, G. Musen and L.R. Squire, Intact priming of words and nonwords in amnesia, Psychobiology 19 (1991), 275285.

[37] E. Halgren, Human hippocampal and amygdala recording and stimulation: Evidence for a neural model of recent memory, in: Neuropsychology of memory, (1st ed.), L.R. Squire and N. Butters, eds., Guilford, New York, 1984, pp. 165-182.

[38] S.B. Hamann and L.R. Squire, Intact perceptual memory in the absence of conscious memory, Behavioral Neuroscience 111 (1997), 850-854.

[39] S.B. Hamann, L.R. Squire and D.L. Schacter, Perceptual thresholds and priming in amnesia, Neuropsychology 9 (1995), 3-15.

[40] R. Henson, T. Shallice and R. Dolan, Neuroimaging evidence for dissociable forms of repetition priming, Science 287 (2000), 1269-1272. 
[41] S.A. Hillyard, K.C. Squires, J.W. Bauer and P.H. Lindsay, Evoked potential correlates of auditory signal detection, Science 172 (1971), 1357-1360.

[42] J.R. Hodges and K.S. Graham, A reversal of the temporal gradient for famous person knowledge in semantic dementia: Implications for the neural organisation of long-term memory, Neuropsychologia 36 (1998), 803-825.

[43] L.L. Jacoby and M. Dallas, On the relationship between autobiographical memory and perceptual learning, Journal of Experimental Psychology: General 110 (1981), 306-340.

[44] T.W. James, G.K. Humphrey, J.S. Gati, R.S. Menon and M.A. Goodale, Repetition priming and the time course of object recognition: An fMRI study, Neuroreport 10 (1999), 1019-1023.

[45] M.K. Johnson, J. Kounios and S.F. Nolde, Electrophysiological brain activity and memory source monitoring, Neuroreport 8 (1997), 1317-1320.

[46] R. Johnson, Jr., Event-related potential insights into the neurobiology of memory systems, in: Handbook of neuropsychology, F. Boller and J. Grafman, eds., (Vol. 10), Elsevier, Amsterdam, 1995, pp. 135-163.

[47] R. Johnson, Jr., K. Kreiter, B. Russo and J. Zhu, A spatiotemporal analysis of recognition-related event-related brain potentials, International Journal of Psychophysiology 29 (1998), 83-104.

[48] R. Johnson, Jr., A. Pfefferbaum and B.S. Kopell, P300 and long-term memory: Latency predicts recognition performance, Psychophysiology 22 (1985), 497-507.

[49] C.A. Joyce, K.A. Paller, H.K. McIsaac and M. Kutas, Effects of feature manipulations on brain potentials during a lexical decision test, Society for Neuroscience Abstracts 22 (1996), 1123.

[50] C.A. Joyce, K.A. Paller, H.K. McIsaac and M. Kutas, Memory changes with normal aging: Behavioral and electrophysiological measures, Psychophysiology 35 (1998), 669-678.

[51] C.A. Joyce, K.A. Paller, T.J. Schwartz and M. Kutas, An electrophysiological analysis of modality-specific aspects of word repetition, Psychophysiology 36 (1999), 655-665.

[52] N. Kapur, Focal retrograde amnesia in neurological disease: A critical review, Cortex 29 (1993), 217-234.

[53] D. Karis, M. Fabiani and E. Donchin, "P300" and memory: Individual differences in the von Restorff effect, Cognitive Psychology 16 (1984), 177-216.

[54] M.M. Keane, J.D. Gabrieli, H.C. Mapstone, K.A. Johnson and S. Corkin, Double dissociation of memory capacities after bilateral occipital-lobe or medial temporal-lobe lesions, Brain 118 (1995), 1129-1148.

[55] W. Klimesch, EEG alpha and theta oscillations reflect cognitive and memory performance: a review and analysis, Brain Research Reviews 29 (1999), 169-195.

[56] R.T. Knight and M. Grabowecky, Escape from linear time: Prefrontal cortex and conscious experience, in: The cognitive neurosciences, M.S. Gazzaniga, ed., MIT Press, Cambridge, MA, USA, 1995, pp. 1357-1371.

[57] M. Kutas, Review of event-related potential studies of memory, in: Perspectives in memory research, M.S. Gazzaniga, ed., MIT Press, Cambridge MA, 1988, pp. 181-218.

[58] M. Kutas and A. Dale, Electrical and magnetic readings of mental functions, in: Cognitive neuroscience, M.D. Rugg, ed., MIT Press, Cambridge, MA, 1997, pp. 197-242.

[59] M. Kutas and K.D. Federmeier, Minding the body, Psychophysiology 35 (1998), 135-150.

[60] G. Mandler, Recognizing: The judgment of previous occurrence, Psychological Review 87 (1980), 252-271.
[61] G.R. Mangun, J.B. Hopfinger and H.J. Heinze, Integrating electrophysiology and neuroimaging in the study of human cognition, Behavior Research Methods, Instruments, \& Computers 30 (1998), 118-130.

[62] H.J. Markowitsch, Which brain regions are critically involved in the retrieval of old episodic memory? Brain Research Reviews 21 (1995), 117-127.

[63] A.R. Mayes, Human organic memory disorders, Cambridge; New York: Cambridge University Press, 1988.

[64] A.R. Mayes and J.J. Downes, Theories of organic amnesia, East Sussex, UK: Erlbaum, 1997.

[65] A.R. Mayes and P. Gooding, Enhancement of word completion priming in amnesics by cueing with previously novel associates, Neuropsychologia 27 (1989), 1057-1072.

[66] J.L. McClelland, B.L. McNaughton and R.C. O'Reilly, Why there are complementary learning systems in the hippocampus and neocortex: Insights from the successes and failures of connectionist models of learning and memory, Psychological Review 102 (1995), 419-457.

[67] M.M. Mesulam, From sensation to cognition, Brain 121 (1998), 1013-1052.

[68] E.K. Miller and R. Desimone, Parallel neuronal mechanisms for short-term memory, Science 263 (1994), 520-522.

[69] B. Milner, L.R. Squire and E.R. Kandel, Cognitive neuroscience and the study of memory, Neuron 20 (1998), 445468.

[70] M. Mishkin, A memory system in the monkey, Philosophical Transactions of the Royal Society of London 298B (1982), 83-95.

[71] M. Moscovitch, A neuropsychological model of memory and consciousness, in: Neuropsychology of memory, (2nd ed.), L.R. Squire and N. Butters, eds., Guilford, New York, 1992, pp. 5-22.

[72] M. Moscovitch, E. Vriezen and Y. Goshen-Gottstein, Implicit tests of memory in patients with focal lesions and degenerative brain disorders, in: Handbook of neuropsychology, H. Spinnler and F. Boller, eds., Elsevier, Amsterdam, 1993, pp. 133-173.

[73] J.M. Murre, Implicit and explicit memory in amnesia: Some explanations and predictions by the TraceLink model, $\mathrm{Mem}$ ory 5 (1997), 213-232.

[74] G. Musen and L.R. Squire, Implicit learning of color-word associations using a Stroop paradigm, Journal of Experimental Psychology: Learning, Memory, and Cognition 19 (1993), 789-798.

[75] H. Neville, E. Snyder, D. Woods and R. Galambos, Recognition and surprise alter the human visual evoked response, Proceedings of the National Academy of Science USA 79 (1982), 2121-2123.

[76] H.J. Neville, M. Kutas, G. Chesney and A.L. Schmidt, Eventrelated brain potentials during initial encoding and recognition memory of congruous and incongruous words, Journal of Memory \& Language 25 (1986), 75-92.

[77] S.F. Nolde, M.K. Johnson and C.L. Raye, The role of prefrontal cortex during tests of episodic memory, Trends in Cognitive Sciences 2 (1998), 399-406.

[78] J.M. Olichney, C. Van Petten, K.A. Paller, D.P. Salmon, V.J. Iragui and M. Kutas, Word repetition in amnesia: Electrophysiological measures of impaired and spared memory, Brain 123 (2000), 1948-1963.

[79] A.L. Ostergaard, Priming deficits in amnesia: Now you see them, now you don't, Journal of the International Neuropsychological Society 5 (1999), 175-190. 
[80] K.A. Paller, Recall and stem-completion priming have different electrophysiological correlates and are modified differentially by directed forgetting, Journal of Experimental Psychology: Learning, Memory, \& Cognition 16 (1990), 1021-1032.

[81] K.A. Paller, Elektrophysiologische Studien zum Menschlichen Gedächtnis [Electrophysiological studies of human memory], Zeitschrift für Elektroenzephalographie, Elektromyographie und verwandte Gebiete 24 (1993), 24-33.

[82] K.A. Paller, Consolidating dispersed neocortical memories: The missing link in amnesia, Memory 5 (1997), 73-88.

[83] K.A. Paller, Neurocognitive foundations of human memory, in: The psychology of learning and motivation, (Vol. 40), D.L. Medin, ed., Academic Press, San Diego, in press.

[84] K.A. Paller, A. Acharya, B.C. Richardson, O. Plaisant, A.P. Shimamura, B.R. Reed and W.J. Jagust, Functional neuroimaging of cortical dysfunction in alcoholic Korsakoff's syndrome, Journal of Cognitive Neuroscience 9 (1997), 277293.

[85] K.A. Paller, V.S. Bozic, C. Ranganath, M. Grabowecky and $\mathrm{S}$. Yamada, Brain waves following remembered faces index conscious recollection, Cognitive Brain Research 7 (1999), 519-531.

[86] K.A. Paller, B. Gonsalves, M. Grabowecky, V.S. Bozic and S. Yamada, Electrophysiological correlates of recollecting faces of known and unknown individuals, NeuroImage 11 (2000), 98-110.

[87] K.A. Paller and M. Gross, Brain potentials associated with perceptual priming versus explicit remembering during the repetition of visual word-form, Neuropsychologia 36 (1998), 559-571.

[88] K.A. Paller and M. Kutas, Brain potentials during memory retrieval provide neurophysiological support for the distinction between conscious recollection and priming, Journal of Cognitive Neuroscience 4 (1992), 375-391.

[89] K.A. Paller, M. Kutas and A.R. Mayes, Neural correlates of encoding in an incidental learning paradigm, Electroencephalography \& Clinical Neurophysiology 67 (1987), 360371.

[90] K.A. Paller, M. Kutas and H.K. McIsaac, Monitoring conscious recollection via the electrical activity of the brain, Psychological Science 6 (1995), 107-111.

[91] K.A. Paller, M. Kutas and H.K. McIsaac, An electrophysiological measure of priming of visual word-form, Consciousness \& Cognition 7 (1998), 54-66.

[92] K.A. Paller and A.R. Mayes, New-association priming of word identification in normal and amnesic subjects, Cortex 30 (1994), 53-73.

[93] K.A. Paller, A.R. Mayes, M. McDermott, A.D. Pickering and P.R. Meudell, Indirect measures of memory in a durationjudgement task are normal in amnesic patients, Neuropsychologia 29 (1991), 1007-1018.

[94] K.A. Paller, G. McCarthy and C.C. Wood, ERPs predictive of subsequent recall and recognition performance, Biological Psychology 26 (1988), 269-276.

[95] K.A. Paller, C. Ranganath, K.S. LaBar, T.B. Parrish, D.R. Gitelman, V.S. Bozic and M.-M. Mesulam, Neural correlates of memory for faces, 2000, under review.

[96] D.D. Potter, C.D. Pickles, R.C. Roberts and M.D. Rugg, The effects of scopolamine on event-related potentials in a continuous recognition memory task, Psychophysiology 29 (1992), 29-37.

[97] C. Ranganath and K.A. Paller, Frontal brain activity during episodic and semantic retrieval: Insights from event-related potentials, Journal of Cognitive Neuroscience 11 (1999), 598-609.

[98] C. Ranganath and K.A. Paller, Frontal brain potentials during recognition are modulated by requirements to retrieve perceptual detail, Neuron 22 (1999), 605-613.

[99] C. Ranganath and K.A. Paller, Neural correlates of memory retrieval and evaluation, Cognitive Brain Research 9 (2000), 209-222.

[100] P.J. Reber, C.E. Stark and L.R. Squire, Contrasting cortical activity associated with category memory and recognition memory, Learning \& Memory 5 (1998), 420-428.

[101] P.J. Reber, C.E. Stark and L.R. Squire, Cortical areas supporting category learning identified using functional MRI, Proceedings of the National Academy of Science USA 95 (1998), 747-750.

[102] A. Richardson-Klavehn and R.A. Bjork, Measures of memory, Annual Review of Psychology 39 (1988), 475-543.

[103] A. Richardson-Klavehn and J.M. Gardiner, Depth-ofprocessing effects on priming in stem completion: Tests of the voluntary-contamination, conceptual-processing, and lexical-processing hypotheses, Journal of Experimental Psychology: Learning, Memory, \& Cognition 24 (1998), 593609.

[104] H.L. Roediger, III and K.B. \& McDermott, Implicit memory in normal human subjects, in: Handbook of neuropsychology, F. Boller and J. Grafman, eds., (Vol. 8), Elsevier, Amsterdam, 1993, pp. 63-131.

[105] F. Rösler, M. Heil and B. Roder, Slow negative brain potentials as reflections of specific modular resources of cognition, Biological Psychology 45 (1997), 109-141.

[106] E.H. Rubin and D.W. McAdam, Slow potential concomitants of the retrieval process, Electroencephalography and Clinical Neurophysiology 32 (1972), 84-86.

[107] D.S. Ruchkin and S. Sutton, Emmitted P300 potentials and temporal uncertainty, Electroencephalography and Clinical Neurophysiology 45 (1978), 268-277.

[108] M.D. Rugg, Event-related brain potentials dissociate repetition effects of high- and low-frequency words, Memory and Cognition 18 (1990), 367-379.

[109] M.D. Rugg, Event-related potential studies of human memory, in: The cognitive neurosciences, M.S. Gazzaniga, ed., MIT Press, Cambridge, MA, 1995, pp. 789-801.

[110] M.D. Rugg, Convergent approaches to electrophysiological and hemodynamic investigations of memory, Human Brain Mapping 6 (1998), 394-398.

[111] M.D. Rugg and M.C. Doyle, Event-related potentials and recognition memory for low- and high-frequency words, Journal of Cognitive Neuroscience 4 (1992), 69-79.

[112] M.D. Rugg, R.E. Mark, P. Walla, A.M. Schloerscheidt, C.S. Birch and K. Allan, Dissociation of the neural correlates of implicit and explicit memory, Nature 392 (1998), 595-598.

[113] M.D. Rugg and M.E. Nagy, Event-related potentials and recognition memory for words, Electroencephalography and Clinical Neurophysiology 72 (1989), 395-406.

[114] M.D. Rugg, R.C. Roberts, D.D. Potter, C.D. Pickles and M.E. Nagy, Event-related potentials related to recognition memory. Effects of unilateral temporal lobectomy and temporal lobe epilepsy, Brain 114 (1991), 2313-2332.

[115] M.D. Rugg and E.L. Wilding, Retrieval processing and episodic memory, Trends in Cognitive Sciences 4 (2000), $108-115$.

[116] T.F. Sanquist, J.W. Rohrbaugh, K. Syndulko and D.B. Lindsley, Electrocortical signs of levels of processing: Percep- 
tual analysis and recognition memory, Psychophysiology 17 (1980), 568-576.

[117] D.L. Schacter, N.M. Alpert, C.R. Savage, S.L. Rauch and M.S. Albert, Conscious recollection and the human hippocampal formation: evidence from positron emission tomography, Proceedings of the National Academy of Science USA 93 (1996), 321-325.

[118] D.L. Schacter and R.L. Buckner, Priming and the brain, Neuron 20 (1998), 185-195.

[119] D.L. Schacter, C.Y. Chiu and K.N. Ochsner, Implicit memory: A selective review, Annual Review of Neuroscience 16 (1993), 159-182.

[120] D.L. Schacter and P. Graf, Preserved learning in amnesic patients: Perspectives from research on direct priming, Journal of Clinical and Experimental Neuropsychology 8 (1986), 727-743.

[121] D.L. Schacter and E. Tulving, Memory systems 1994, Cambridge, Mass.: MIT Press, 1994.

[122] D.M. Schnyer, J.J. Allen and K.I. Forster, Event-related brain potential examination of implicit memory processes: Masked and unmasked repetition priming, Neuropsychology 11 (1997), 243-260.

[123] D.M. Schnyer, J.J. Allen, A.W. Kaszniak and K.I. Forster, An event-related potential examination of masked and unmasked repetition priming in Alzheimer's disease: Implications for theories of implicit memory, Neuropsychology 13 (1999), 323-337.

[124] A.J. Senkfor and C. Van Petten, Who said what? An eventrelated potential investigation of source and item memory, Journal of Experimental Psychology: Learning, Memory, \& Cognition 24 (1998), 1005-1025.

[125] A.P. Shimamura, Priming effects of amnesia: Evidence for a dissociable memory function, Quarterly Journal of Experimental Psychology 38A (1986), 619-644.

[126] A.P. Shimamura, Neuropsychological analyses of implicit memory: History, methodology, and theoretical interpretations, in: Implicit memory: New directions in cognition, development, and neuropsychology, P. Graf and M.E.J. Masson, eds., Erlbaum, Hillsdale, NJ, 1993, pp. 265-285.

[127] A.P. Shimamura, The role of prefrontal cortex in monitoring and controlling memory processes, in: Implicit memory and metacognition, L. Reder, ed. Erlbaum, Mahwah, NJ, 1996, pp. 259-274.

[128] A.P. Shimamura and L.R. Squire, Impaired priming of new associations in amnesia, Journal of Experimental Psychology: Learning, Memory, \& Cognition 15 (1989), 721-728.

[129] M.E. Smith, Neurophysiological manifestations of recollective experience during recognition memory judgments, Journal of Cognitive Neuroscience 5 (1993), 1-13.

[130] M.E. Smith and K. Guster, Decomposition of recognition memory event-related potentials yields target, repetition, and retrieval effects, Electroencephalography and Clinical Neurophysiology 86 (1993), 335-343.

[131] M.E. Smith and E. Halgren, Dissociation of recognition memory components following temporal lobe lesions, Journal of Experimental Psychology: Learning, Memory, \& Cognition 15 (1989), 50-60.

[132] L.R. Squire, Memory and brain, Oxford: Oxford University
Press, 1987.

[133] L.R. Squire and B.J. Knowlton, The medial temporal lobe, the hippocampus, and the memory systems of the brain, in: The new cognitive neurosciences, (2nd ed.), M.S. Gazzaniga, ed., MIT Press, Cambridge, MA, 2000, pp. 765-779.

[134] L.R. Squire, J.G. Ojemann, F.M. Miezin, S.E. Petersen, T.O. Videen and M.E. Raichle, Activation of the hippocampus in normal humans: A functional anatomical study of memory, Proceedings of the National Academy of Science USA 89 (1992), 1837-1841.

[135] L.R. Squire and K.A. Paller, Biology of memory, in: Kaplan \& Sadock's Comprehensive textbook of psychiatry, (7th ed.), B.J. Sadock and V.A. Sadock, eds., Williams \& Wilkins, Philadelphia, 2000, pp. 425-437.

[136] L.R. Squire, A.P. Shimamura and D.G. Amaral, Memory and the hippocampus, in: Neural models of plasticity, J. Byrne and W. Berry, eds., Academic Press, New York, 1989, pp. 208-239.

[137] D. Swick and R.T. Knight, Contributions of right inferior temporal-occipital cortex to visual word and non-word priming, Neuroreport 7 (1995), 11-16.

[138] D. Swick and R.T. Knight, Event-related potentials differentiate the effects of aging on word and nonword repetition in explicit and implicit memory tasks, Journal of Experimental Psychology: Learning, Memory, \& Cognition 23 (1997), 123-142.

[139] D. Swick and R.T. Knight, Contributions of prefrontal cortex to recognition memory: Electrophysiological and behavioral evidence, Neuropsychology 13 (1999), 155-170.

[140] T.J. Teyler and P. DiScenna, The hippocampal memory indexing theory, Behavioral Neuroscience 100 (1986), 147154.

[141] C.T. Trott, D. Friedman, W. Ritter and M. Fabiani, Item and source memory: Differential age effects revealed by eventrelated potentials, Neuroreport 8 (1997), 3373-3378.

[142] E. Tulving, Memory and consciousness, Canadian Psychology 26 (1985), 1-12.

[143] A.D. Wagner, D.L. Schacter, M. Rotte, W. Koutstaal, A. Maril, A.M. Dale, B.R. Rosen and R.L. Buckner, Building memories: Remembering and forgetting of verbal experiences as predicted by brain activity, Science 281 (1998), 1188-1191.

[144] L.R. Warren, Evoked potential correlates of recognition memory, Biological Psychology 11 (1980), 21-35.

[145] S. Weiss and P. Rappelsberger, Long-range EEG synchronization during word encoding correlates with successful memory performance, Cognitive Brain Research 9 (2000), 299-312.

[146] C.L. Wiggs and A. Martin, Properties and mechanisms of perceptual priming, Current Opinion in Neurobiology 8 (1998), 227-233.

[147] E.L. Wilding, M.C. Doyle and M.D. Rugg, Recognition memory with and without retrieval of context: An eventrelated potential study, Neuropsychologia 33 (1995), 743767.

[148] E.L. Wilding and M.D. Rugg, An event-related potential study of recognition memory with and without retrieval of source, Brain 119 (1996), 889-905. 


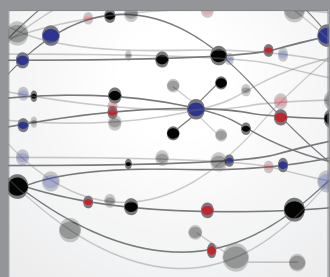

The Scientific World Journal
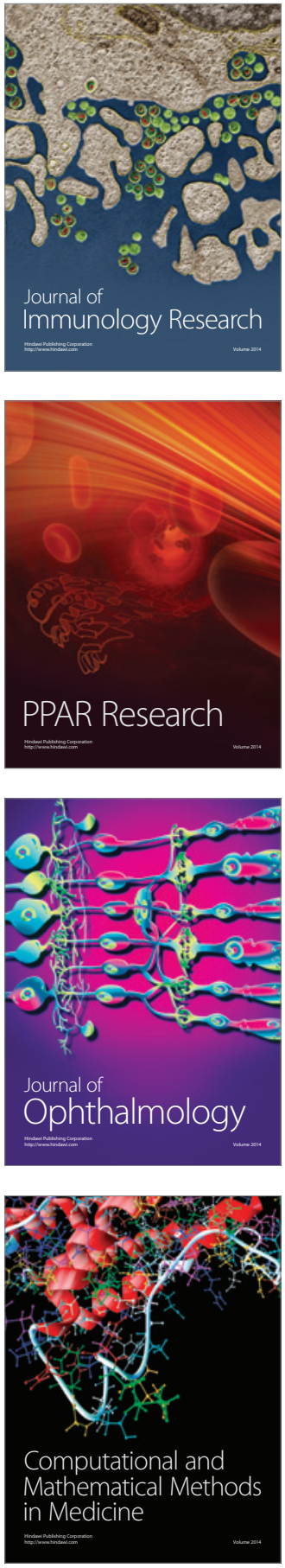

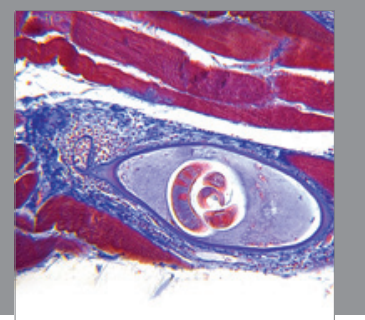

Gastroenterology

Research and Practice
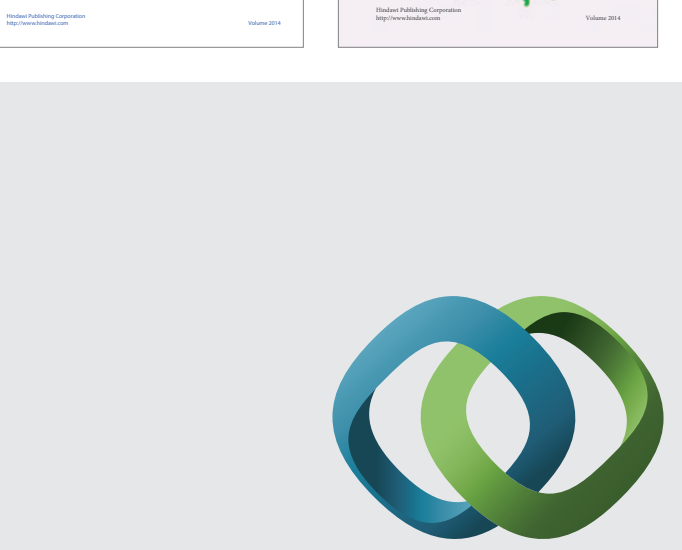

\section{Hindawi}

Submit your manuscripts at

http://www.hindawi.com
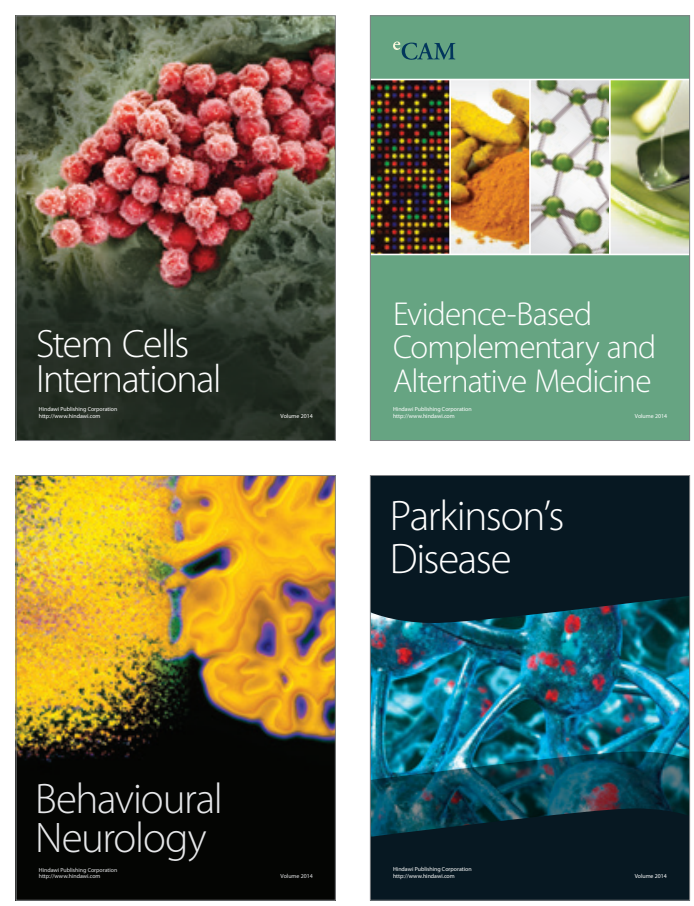

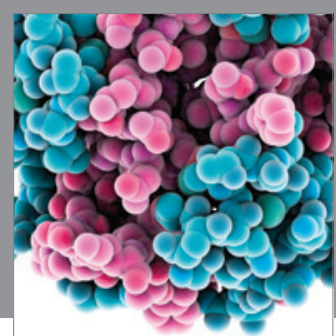

Journal of
Diabetes Research

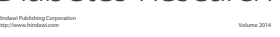

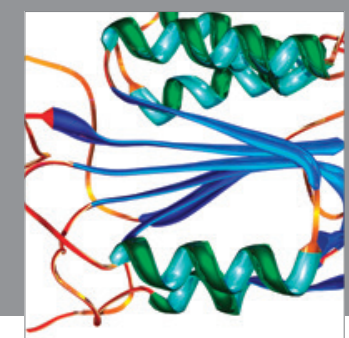

Disease Markers
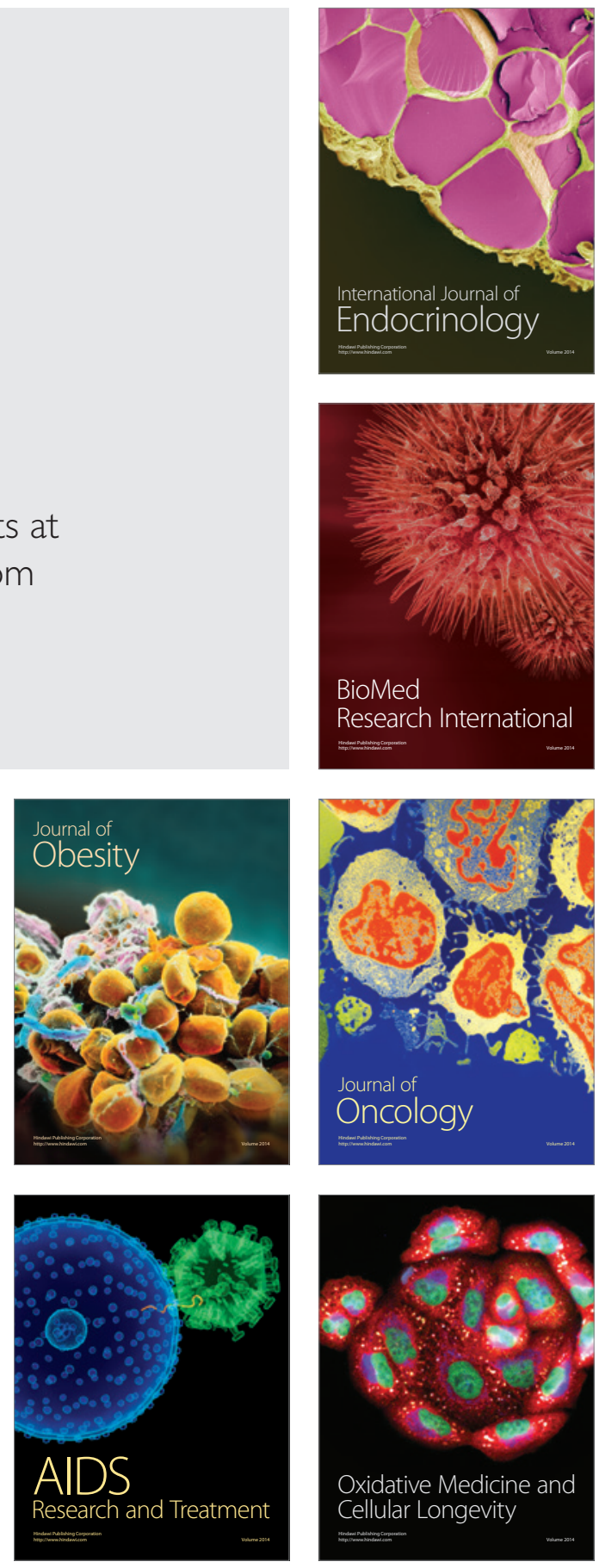